\title{
Lif İçeren ve İçermeyen Enteral Ürünlerle Beslenen Hastalarda Gastrik Rezidüel Volüm ve Gastrointestinal Komplikasyonların Karşılaştırılması
}

\author{
Comparison of Gastric Residuel Volumes and Gastrointestinal \\ Complications in Patients Fed with Enteral Formulas with \\ Fiber and without Fiber
}

Cihan Sedat Aytünür, Namık Özcan*, Ayşe Özcan*, Çetin Kaymak*, Hülya Başar*, Bektaş Köse*

Tirebolu Devlet Hastanesi, Anesteziyoloji ve Reanimasyon Kliniği, Giresun, Türkiye

*Ankara Eğitim ve Araştırma Hastanesi, Anesteziyoloji ve Reanimasyon Kliniği, Ankara, Türkiye

\section{ÖZET}

Amaç: Çalışmada, enteral nutrisyona standart lifli ve lifsiz ürünle başlanan ve devam edilen hastalarda gastrik rezidüel volüm (GRV) ve gastrointestinal komplikasyonların karşılaştıııması amaçlanmıştır. Gereç ve Yöntem: Yoğun Bakım Ünitesi'nde mekanik ventilasyon desteği altında 10 günden fazla kalması beklenen ve nazogastrik ile enteral yoldan beslenecek 60 hasta çalışmaya alındı. Hastalar randomize olarak iki gruba ayrıldı. Lifsiz grup; standart izoosmolar (Osmolite, Abbott, Illinois, USA) ürünle, Lifli grup; standart lifli izoosmolar ürünle (Jevity, Zwolle, Holland) beslenmeye başlandı. Hedeflenen maksimum kalori değerine ulașmış hastalar 3 gün süre ile takip edildi. Her gün 3 kez GRV ölçüldü. Abdominal distansiyon, kusma, regürjitasyon, aspirasyon, ishal gibi komplikasyonlar kaydedildi.

Bulgular: Hastaların 3 günlük izlemleri boyunca grupların GRV'leri arasında anlamlı istatistiksel farklılık bulunmamıstır. Kusma, regürjitasyon ve distansiyon açısından gruplar arasında istatistiksel olarak anlamlı farklılık gözlenmemiştir. Hiçbir hastada ishal ve aspirasyon gerçekleșmemiștir. Calıșma süresince Lifli grupta 20 $(\% 66,66)$, Lifsiz grupta $17(\% 56,66)$ hastada en az 1 komplikasyon gözlenmiștir. Gruplar arası fark istatistiksel olarak anlamlı değildir. Sonuç: Sonuç olarak enteral nutrisyona lif içeren veya içermeyen standart ürünle başlanan ve devam edilen hastalarda GRV ve gastrointestinal komplikasyonlar açısından istatistiksel fark bulunmamıştır. (Türk Yoğun Bakım Derneği Dergisi 2012; 10: 46-51) Anahtar Kelimeler: Enteral beslenme, kusma, respiratuar aspirasyon komplikasyon

\section{SUMMARY}

Objective: The aim of this study is to compare gastric residuel volumes (GRV) and gastrointestinal complications in patients which enteral nutrition is started and continued with formulas with and without fiber. Material and Method: Sixty patients which were mechanically ventilated, and expected to stay more than 10 days in ICU and fed enterally with nasogastric tube were enrolled to the study. Patients were randomised into two study groups. Without-fiber Group was fed with standart isoosmolar formula (Osmolite, Abbott, Illinoisi USA). Fiber Group was fed with standart isoosmolar fiber formula (Jevity, Zwolle, Holland). Patients who reached targetted maximum calorie value were monitored for 3 days. GRV's were measured 3 times a day. Gastrointestinal complications which are abdominal distension, vomitting, regurgitation, aspiration, diarrhea episodes were registered. Results: For 3 days of follow up, there was no statistically significant difference comparing the GRV's of the groups. Vomitting, regurgitation and distension were not different between groups. Diarrhea and aspiration were not observed in either groups. In 20 patients $(66.66 \%)$ in Fiber group and in 17 patients $(56.66 \%)$ in Without-Fiber Group at least one complication was observed. The difference between groups was statistically insignificant.

Conclusion: As a conclusion, in patients which enteral nutrition is started and continued with an enteral formula with and without fiber, there was no statistically significant difference comparing GRV's and gastrointestinal complications. (Journal of the Turkish Society Intensive Care 2012; 10: 46-51)

Key Words: Enteral nutrition, vomiting, respiratory aspiration, complication

Yazışma Adresi/Address for Correspondence: Dr. Namık Özcan, Ankara Eğitim ve Araştırma Hastanesi, Anesteziyoloji ve Reanimasyon Kliniği, Ankara, Türkiye Tel.: +90 3125953175 E-posta: namikozcan@gmail.com Geliș Tarihi/Received: 15.03.2012 Kabul Tarihi/Accepted: 19.04.2012 


\section{Giriş}

Lifsiz izoosmolar ürünler, bazı hastalarda, dışkı miktarını, sıklığını ve dışkının sıvı içeriğini azaltabilirler. Lifli ürünlerin kullanımı, barsakta sindirilemeyen içeriklerinin (soya polisakkaritleri, Arap zamkı, selüloz, inülin, pektin, fruktooligosakkaritler) yardımıyla bu gibi komplikasyonların oluşumuna yüksek oranda engel olur (1).

Enteral beslenme uygulamaları gastrointestinal intolerans veya disfonksiyon (kusma, gastrik distansiyon, yüksek gastrik rezidüel volüm [GRV], diyare) nedeniyle sıklıkla kesintiye uğrayabilmektedir (2-4).

Bu çalışmada enteral nutrisyona standart lifli ve lifsiz ürünle başlanan ve devam edilen mekanik ventilatöre bağlı yoğun bakım hastalarında, GRV ve gastrointestinal komplikasyonların karşılaştırılması amaçlanmıştır.

\section{Gereç ve Yöntem}

Çalışma, Ankara Eğitim ve Araştırma Hastanesi, etik kurulu tarafından onaylandıktan sonra, Anesteziyoloji ve Reanimasyon Kliniği Yoğun Bakım Ünitesi'nde mekanik ventilasyon desteği altında en az 10 gün kalması beklenen ve nazogastrik sonda ile enteral yoldan beslenmeye başlanacak 60 hasta çalışmaya dahil edildi. Hasta ve/veya hasta yakınları çalışma hakkında bilgilendirilerek yazılı onamları alındı. Mekanik barsak obstrüksiyonu, paralitik ileus, generalize peritonit, akut pankreatit, enflamatuar barsak hastalığı, barsak fistülü, gastrointestinal kanama, kısa barsak sendromu, morbid obezite (Vücut kitle indeksi >40), gastrostomi/ jejunostomi açılmış hastalar, nazogastrik tüpleri ileumda olanlar, ventilatör ile ciddi uyumsuzluğu olan hastalar, herhangi bir nedenle sedasyona ihtiyaç duyan hastalar, gastrointestinal sistem motilitesini etkileyebilecek ilaçları kullananlar, kafa travması olan hastalar, hesaplanan maksimum kalori değerine enteral yoldan ulaşamayan hastalar, çalışma dışı bırakıldı. Çalışmaya dahil olan tüm hastalara prokinetik olarak metoklopropamid 3×10 mg i.v. başlandı. Hastaların hedeflenen maksimum kalorileri Schofield formülü kullanılarak hesaplandı. Tüm hastalar hedeflenen maksimum kalori değerine enteral yoldan ulaşana dek eksik kalan kalorileri parenteral yoldan kombine edilerek tamamlandı. Hedeflenen maksimum kalori değerine enteral yoldan ulaşan hastalar izleme alındı.

Toplam 60 hasta, dörtlü rastgele permütasyon blokları metodu kullanılarak iki çalışma grubuna randomize edildi.

Lifsiz grup: Standart izoosmolar ürünle (Osmolite, Abbott, Illinois, USA),

Lifli grup: Standart lifli izoosmolar ürünle (Jevity, Zwolle, Holland), (10,6 g L-1 suda çözünen ve çözünmeyen diyet lifi ve $7 \mathrm{~g} \mathrm{~L}$-1 fruktooligosakkarit içerir) $30 \mathrm{ml} \mathrm{st-1}$ dozunda beslenmeye başlandı. Komplikasyon görülmeyen hastalarda doz 8 saatte bir $20 \mathrm{ml} \mathrm{st-1}$ artırıldı. Tüm hastalarda 24:0008:00 saatleri arasında enteral beslenmeye ara verildi, nazogastrik tüpler su verilip sabaha dek kapalı tutuldu. Hasta yataklarının çalışma süresince yer ile kırk beş derece açı yapacak şekilde baş taraflarının yüksekte tutulmasına dikkat edildi.

Tüm hastaların, yaş cinsiyet, boy, kilo, hedeflenen maksimum kalori düzeyleri, APACHE II skorları, maksimum kaloriye ulaştıkları günden sonra uygulanan PEEP düzeyleri ve maksimum kaloriye ulaşma zamanları kaydedildi.

Hedeflenen maksimum kalori değerine ulaşmış hastalar 3 gün süre ile takip edildi. Hergün saat 08:00, 16:00 ve 24:00'de nazogastrikleri 50 ml'lik enjektörle aspire edilerek gelen volüm ölçüldü ve kaydedildi (2). Üç gün boyunca aşağıdaki komplikasyonlardan herhangi biri gelişirse, zamanı ile birlikte kaydedildi.

GRV'leri 200 ml fazla olan ve aşağıdaki komplikasyonların herhangi biri görülen hastada beslenmeye 6 saat ara verildi. Altı saat sonra GRV tekrar ölçüldü, $200 \mathrm{ml}$ üzerinde değilse beslenmeye aynı dozla takibe devam edildi, $200 \mathrm{ml}$ üzerinde olduğu durumlarda infüzyon hızı yarıya indirilerek hasta yakın gözlem altına alındı.

\section{Komplikasyonlar}

- Abdominal distansiyon

- Kusma (ağızdan enteral formülün basınçla gelmesi) (5)

- Regürjitasyon (enteral formülün ağız ya da burundan aspirasyonla ya da sızma şeklinde gelmesi) (5)

- Aspirasyon (tüp ya da trakeostomi kanülünden enteral formül gelmesi)

- Ishal (24 saatte 5 ten fazla sulu gaita ya da 2000 ml'den fazla sulu gaita) (5). Gaita miktarının hasta alt bezlerinin ağırlıkları tartılarak belirlenmesi planlandı.

Montejo JC ve ark. çalışmalarında enteral beslenmenin komplikasyon hızlarını bir grupları için \%48 olarak bildirmişlerdir (5). Biz de çalışmamızda, iki grup arasında komplikasyon hızları arası farkı \%30 olarak tespit edebilmek için, Tip I hata $(\alpha=0,01)$, Tip II hata $(\beta=0,20)$ olacak şekilde örneklem büyüklüğünü her bir grup için minimum 55 olarak hesapladık. Ancak yoğun bakımımızda toplam 110 hasta sayısına ulaşmak çok uzun süreceğinden, çalışma süresini kısaltmak adına $\alpha$ değerini 0,1 alarak örneklem büyüklüğünü her bir grup için 29 olarak hesapladık. Çalışmamızda Tip II hata değerini 0,20 olarak kabul ettiğimizden yapılacak hipotez testinin gücü 0,80 (\%80'dir.

Verilerin istatistiksel analizinde MedCalc Version 11.3.3.0 (MedCalc Software, Mariakerke, Belgium) istatistik paket programı kullanıldı. Veri giriş kontrolleri yapıldıktan sonra 
istatistiksel analizler gerçekleştirildi. Ölçümle elde edilen değişkenlerin, Kolmogorov-Simirnov testi ile dağlımları test edildi. Iki grup arası karşılaştırmalarda, çarpık dağılım gösteren veriler için Mann-Whitney $U$ testi, normal dağılım gösteren veriler için $\mathrm{t}$ testi kullanıldı. Veriler, ortalama \pm standart sapma ve ortanca (en küçük-en büyük) olarak verildi. Sayımla elde edilen verilerin gruplar arası karşılaştırımasında ki-kare testi kullanıldı. Veriler yüzde ya da oran olarak verildi. p'nin 0,05'ten küçük olduğu değerler istatistiksel olarak anlamlı kabul edildi.

\section{Bulgular}

Hastaların, yaş, vücut ağırlığı, boy, vücut kitle indeksi, hedeflenen maksimum kalori değerleri, APACHE II skorları, maksimum kaloriye ulaşıldığı günden sonra uygulanmakta olan PEEP değerleri ve maksimum kaloriye ulaşma zamanları açısından iki grup arasında istatistiksel olarak anlamlı farklılık bulunmamıştır (Tablo 1).

Hastaların 3 günlük izlemleri boyunca grupların gastrik rezidüel volümleri benzer bulunmuştur (Tablo 2).

Hastalarda takip edilen komplikasyonlardan; kusma 1. gün her iki grupta da izlenmemiştir. 2. gün lifsiz grupta 2 $(\% 6,66)$; lifli grupta $2(\% 6,66)(p=0,60), 3$. gün lifsiz grupta 4 $(\% 13,33)$, lifli grupta $3(\% 10)(p=1,00)$ hastada izlenmiştir. Kusma sayıları bakımından gruplar arasında istatistiksel olarak anlamlı fark bulunmamıştır (Tablo 3).

Gruplar arası regürjitasyon oranları karşılaştırıldığında istatistiksel olarak anlamlı farklıı̆a rastlanmamıştır (Tablo 3).

Izlem süresince gruplarda istatistiksel olarak benzer oranlarda distansiyon gözlenmiştir (Tablo 3). Distansiyon gelişen hastalardan hiçbirinin tablosu beslenmeyi sonlandıracak kadar ciddiye dönmemiş, nutrisyona ara verilmesinde birkaç saat sonra normale dönmüştür.

Hastaların 3 günlük takipleri boyunca çalışma protokolünde kabul edilen anlamda ishal olgusuna rastlanmamıştır (5). Ancak lifli ürünle beslenen hastaların lifsiz ürünle beslenen hastalara göre daha yumuşak kıvamlı dışkıladıkları subjektif bir gözlem olarak dikkati çekmiştir.

Izlem süresi boyunca hiçbir hastada aspirasyon gözlenmemiştir.

Çalışma süresince Lifli grupta $20(\% 66,66)$, Lifsiz grupta 17 (\%56,66) hastada en az 1 komplikasyon gözlenmiştir. Gruplar arası fark istatistiksel olarak anlamlı bulunmamıştır $(p=0,59)$.

\section{Tartışma}

Bu çalışmada, lifli standart ve lifsiz standart izoosmolar ürünle enteral beslenmeye başlanan hastalarda gastrik rezidüel volüm ve gastrointestinal komplikasyonlar açısından gruplar arasında istatistiksel olarak anlamlı farklılık saptanmamıştır.

Fizyolojik bir beslenme yöntemi olan enteral beslenme; GIS fonksiyonlarının normal veya normale yakın olduğu durumlarda, besin maddelerinin nazoenterik (nazogastrik, nazojejunal), gastrostomi veya jejunostomi yoluyla sürekli ya da aralıklı olarak hastaya verilmesi olarak tanımlanmaktadır (4,6-8).

Klinik pratikte hastaların beslenmesi sıklıkla ihmal edilebilmektedir. Beslenme uygulamaları, yoğun bakım hastalarında stres cevabın oluşturulmasında ve sağkalımda önemli rol oynar (9). Enteral beslenme, immün fonksiyonları güçlendirme nedeniyle tercih edildiği gibi, parenteral

Tablo 1. Hastaların temel özellikleri

\begin{tabular}{|c|c|c|c|}
\hline & Lifsiz Grup ( $n=30)$ & Lifli Grup $\quad(n=30)$ & $\mathbf{p}$ \\
\hline $\begin{array}{l}\text { Yaş (yıl) (Ort_SS) } \\
\text { (ortanca (en küçük-en büyük)) }\end{array}$ & $\begin{array}{c}46,13 \pm 28,50 \\
61(13-81)\end{array}$ & $\begin{array}{c}44,63 \pm 20,52 \\
32(30-83)\end{array}$ & $0,30^{*}$ \\
\hline Vücut ağıllığı (kg) (OrtıSS) & $65,17 \pm 14,90$ & $62,23 \pm 4,00$ & $0,45^{\star *}$ \\
\hline VKi (kg m²) (Ort $\pm S S)$ & $22,73 \pm 5,53$ & $23,43 \pm 2,43$ & $0,06^{\star *}$ \\
\hline Boy $(\mathrm{cm})$ (OrttSS) & $164,90 \pm 4,16$ & $164,97 \pm 10,25$ & $0,23^{* *}$ \\
\hline Cinsiyet (E/K) & $16 / 14$ & $9 / 21$ & $0,15^{* * *}$ \\
\hline 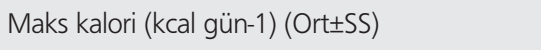 & $1955,00 \pm 447,007$ & $1867,00 \pm 120,18$ & $0,45^{\star *}$ \\
\hline $\begin{array}{l}\text { Maks kalori ulaşma zamanı (gün) } \\
\text { (ortanca [en küçük-en büyük]) }\end{array}$ & $4(3-6)$ & $4(3-6)$ & $0,44^{\star}$ \\
\hline APECHE II (ortanca [en küçük-en büyük]) & $20(17-26)$ & $19(19-21)$ & $0,75^{\star}$ \\
\hline PEEP (cm H $\mathrm{H}_{2} \mathrm{O}$ ) (ortanca (en küçük-en büyük)) & $6(5-7)$ & $6(5-7)$ & $0,61^{*}$ \\
\hline
\end{tabular}




\begin{tabular}{|c|c|c|c|c|}
\hline İzlem Günü & Saat & 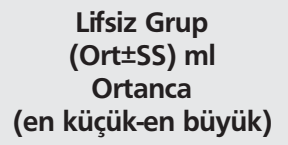 & 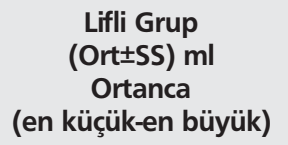 & $p$ \\
\hline \multirow[t]{3}{*}{ 1. gün } & 08.00 & $\begin{array}{c}34,67 \pm 44,16 \\
20(0-160)\end{array}$ & $\begin{array}{c}32,17 \pm 47,61 \\
5(0-180)\end{array}$ & $0,42^{*}$ \\
\hline & 16.00 & $\begin{array}{c}47,50 \pm 53,27 \\
35(0-220)\end{array}$ & $\begin{array}{c}57,67 \pm 85,92 \\
25(0-370)\end{array}$ & 0,91 * \\
\hline & 24.00 & $\begin{array}{l}48,00 \pm 69,74 \\
22,5(0-170)\end{array}$ & $\begin{array}{c}58,33 \pm 69,04 \\
40(0-250)\end{array}$ & $0,68^{*}$ \\
\hline \multirow[t]{3}{*}{ 2. gün } & 08.00 & $\begin{array}{c}46,33 \pm 63,87 \\
15(0-220)\end{array}$ & $\begin{array}{l}54,33 \pm 81,32 \\
17,5(0-300)\end{array}$ & $0,89^{*}$ \\
\hline & 16.00 & $\begin{array}{r}48,83 \pm 69,74 \\
12,5(0-250)\end{array}$ & $\begin{array}{c}43,00 \pm 97,49 \\
0(0-400)\end{array}$ & $0,21^{*}$ \\
\hline & 24.00 & $\begin{array}{c}45,00 \pm 72,08 \\
2,5(0-300)\end{array}$ & $\begin{array}{c}47,83 \pm 116,07 \\
0(0-500)\end{array}$ & $0,15^{*}$ \\
\hline \multirow[t]{3}{*}{ 3. gün } & 08.00 & $\begin{array}{c}35,33 \pm 67,09 \\
0(0-270)\end{array}$ & $\begin{array}{c}56,83 \pm 92,80 \\
0(0-300)\end{array}$ & 0,31 * \\
\hline & 16.00 & $\begin{array}{c}44,33 \pm 64,82 \\
0(0-200)\end{array}$ & $\begin{array}{c}60,83 \pm 88,70 \\
0(0-300)\end{array}$ & $0,54^{*}$ \\
\hline & 24.00 & $\begin{array}{c}30,50 \pm 49,49 \\
0(0-180)\end{array}$ & $\begin{array}{c}85,67 \pm 168,84 \\
0(0-700)\end{array}$ & $0,65^{*}$ \\
\hline
\end{tabular}

\section{Tablo 3. Grupların, kusma, regürjitasyon, distansiyon açısından karşılaştırılması}

\begin{tabular}{lcccc} 
Komplikasyon & İzlem Günü & $\begin{array}{c}\text { Lifsiz Grup } \\
\text { (n) (\%) }\end{array}$ & $\begin{array}{c}\text { Lifli Grup } \\
\text { (n) (\%) }\end{array}$ & $p$ \\
\hline Kusma & 1. gün & $0(0)$ & $0(0)$ & $1,00^{*}$ \\
& 2. gün & $2(6,66)$ & $2(6,66)$ & $0,60^{*}$ \\
Regürjitasyon & 3. gün & $4(13,33)$ & $3(10)$ & $1,00^{*}$ \\
& 1. gün & $0(0)$ & $1(3,33)$ & $1,00^{*}$ \\
Distansiyon & 2. gün & $8(26,66)$ & $8(26,66)$ & $0,77^{*}$ \\
& 3. gün & $6(20)$ & $6(20)$ & $0,75^{*}$ \\
1. gün & 2. gün & $4(13,33)$ & $7(13,33)$ & $0,70^{*}$ \\
*: Kikare testi & 3. gün & $2(6,66)$ & $3(10)$ & $0,15^{*}$ \\
\end{tabular}

beslenme ile kıyaslandığında beslenme tedavisinin maliyetini düşürmesi açısından da değerlidir $(10,11)$.

Enteral nutrisyon \%30-40 hastada çeşitli nedenlerle kesintiye uğrar (3). Bu ara vermenin en önemli nedeni gastrointestinal motilite bozukluğudur (7). Motilite bozukluğunun sonucu olarak klinikte, GRV'de artma, kusma, regürjitasyon, distansiyon, ishal, aspirasyon görülür. Komplikasyonların azaltılması için enteral nutrisyona izoosmolar ürünlerle başlanır ve düşük başlangıç dozu hastanın toleransına göre artırılır. Klinisyenler, enteral nutrisyona başlarken, osmolariteleri ve kalori değerleri benzer olmasına rağmen lifsiz ürünleri tercih etmektedirler. Biz çalışmamızda lif içeren ve içermeyen izoosmolar ürünlerle beslenen hastalarda GRV ve komplikasyon oranlarını karşılaştırmayı amaçladık.

$\mathrm{GRV}$, enteral beslenme sırasında midede kalan besin miktarının ölçülmesi ile belirlenir. Ölçüm, nazogastrik veya beslenme tüpünden midedeki içeriğin enjektör ile aspire edilmesi ya da ölçülü bir kaba drene edilerek miktarının belirlenmesi ile yapılır (2). GRV, çok faktörden etkilenen bir 
parametre olduğu için, enteral beslenmeye intoleransın belirlenmesinde tek başına kullanılamaz. GRV'nin sınır değerinin ne olması gerektiği ile ilgili olarak $50 \mathrm{ml}$ ile $500 \mathrm{ml}$ arasında birçok değer test edilmiştir. Sonuç olarak bir eşik değer ile komplikasyonlar arasında korelasyon tespit edilememiştir. Bugün literatürde $200 \mathrm{ml}$ değeri GRV için eşik kabul edilmektedir. Yüksek GRV değerleri ile karşılaşmamak için opioid ve dopamin kullanımında dikkatli olunması, elektrolit bozuklukları ve hiperglisemiden kaçınılması önerilmektedir (1,4,12-14). Bizim çalışmamızda lifli grupta GRV değerleri lifsiz gruba benzer seyretmiştir.

Artmış GRV'nin en önemli sonuçlarından biri kusmadır. Enteral besleme sırasında kusma oranları literatürde \%6 ile \%53 oranında bildirilmiştir $(4,12,15,16)$. Bizim çalışmamızda günlere göre \%0 ile \%13,33 arasında kusma oranlarına rastladık. Lifli ve Lifsiz ürünle beslenen gruplar arasında kusma yönünden klinik ve istatiksel farklılığa rastlanmamıştır. Çalışmamızda kusma oranlarının literatüre oranla daha düşük olmasının nedeni kafa travmalı hastaların çalışma dışı bırakılması, tüm hastalara motilite artırıcı ajanların verilmesi ve takip süresinin 3 gün ile kısıtlı tutulması olabilir.

Regürjitasyonun, literatür incelendiğinde sık değerlendirilen bir parametre olmadığı görülmektedir. Oranı bir çalışmada \%5,1 ile \%7,1 arasında bildirilmiştir (5). Bizim çalışmamızda günlere göre $\% 0$ ile $\% 26,6$ arasında seyretmiştir. Lifli ve Lifsiz grup karşılaştırıldığında iki grup arasında istatistiksel olarak anlamlı farklılığa rastlanmamıştır.

Distansiyon, enteral nutrisyon sırasında dikkat edilmesi gereken en önemli komplikasyonlardandır. Literatürde distansiyon oranları için hasta gruplarına göre değişen rakamlar verilmektedir $(\% 10-19,4)(5,17)$. Çalışmamızda bu oran \%6.66 ile \%23,33 arasında değişmektedir. Lifli ve Lifsiz grup distansiyon açısından istatistiksel olarak değerlendirildiğinde aralarında fark bulunmamıştır, ancak lifli ürünle beslenen grupta sayısal olarak daha fazla distansiyona rastlanmıştır. Hiçbir hastamızda distansiyon nedeniyle nutrisyonu sonlandırma gereği olmamıştır. Nutrisyona 6 saat süreyle ara verildikten sonra tablolar gerilemiş ve nutrisyona kalındığı yerden devam edilmiştir. Distansiyonun Lifli grupta sayısal oranda fazla olması, bu ürünlerin lif içeriğinin daha fazla barsak gazı oluşturmasına bağlanmıştır.

Ishal 24 saat içerisinde 5'ten fazla sıvı veya toplam 2000 ml'den fazla sıvı hacimde dışkılama olarak tanımlanmaktadır (5). Bu açıdan bakıldığında hastalarımızın hiçbirinde ishalle karşılaşılmamıştır. Literatür incelendiğinde, ishal oranları \%11 ile \%25 arasında değişmektedir $(5,12,15,17)$. Bu oranın literatüre göre düşük olmasının nedeni ürünleri daha düşük dozlarda başlayıp, daha yavaş doz artırmamıza bağıı olabilir.

Beslenme sırasında aspirasyon pnömoniye neden olabilir. Ancak aspirasyon sonrası ne oranda pnömoni geliştiği bilinmemektedir. Enteral formül aspirasyonu sonucu antibiyotik gerektiren pnömoni oranı \%1-4 gibi düşük bir orandadır. Mortalitesi ise daha da düşüktür. Aspirasyonun GRV ile de ilişkisi gösterilememiştir. Çalışmamızdaki her iki grupta da aspirasyon gözlenmemiştir. Bu sonuç literatürdeki düşük oranlarla da uyumludur $(4,5)$.

Çalışmamızda, lifli grupta 20 hastada $(\% 66,66)$, lifsiz grupta 17 hastada $(\% 56,66)$ en az bir kez herhangi bir komplikasyon nedeniyle enteral nutrisyona ara verilmek zorunda kalınmıştır. Literatür incelendiğinde bu oran \%30 ile 63 arasında değişen değerlerdedir $(4,5,12,15,17)$. Bizim çalışmamızın sonuçları literatürdeki sonuçların üst sınırına yakındır. Ancak gruplarımız arasında istatistiksel olarak anlamlı farklılık yoktur. Bu sonuç bize lif içerikleri farklı olsa da standart izoosmolar ürünlerin benzer komplikasyon oranlarına sahip olduğunu göstermektedir. Ayrıca bu sonuçlar göz önüne alındığında enteral nutrisyon sırasında gastrointestinal komplikasyonlara sıkça rastlandığından, tedavi sırasında hasta güvenliği açısından dikkatli olunması gerektiği ortadadır.

Çalışmamızda izlem süresinin 3 gün ile sınırlı olması çalışmamızın eksik yönüdür. $\mathrm{Bu}$ nedenle bazı komplikasyon oranlarını gerçek değerlerinden daha fazla ya da daha az görmüş olmamız mümkündür. Çalışmaya başlamadan önce yaptığımız ön çalışmada hastaların 10 gün süre ile izlenmesi planlamıştır, ancak bu süre içerisinde hastaların ventilatör uyumu gibi birçok sebeple birkaç kez sedasyona intiyaç duymaları sebebi ile standardizasyon sağlanamamış, birçok hasta çalışma dışında bırakılmıştır. Gruplar arası standardizasyonu sağlayabilmek adına izlem süresi kısaltılmıştır.

Bu çalışmada, lifli standart ve lifsiz standart izoosmolar ürünle enteral beslenmeye başlanan hastaların gastrik rezidüel volüm ve gastrointestinal komplikasyonlar açısından karşılaştıııması amaçlanmıştır. Çalışmada, gruplar arasında gastrik rezidüel volüm ve gastrointestinal komplikasyonlar açısından istatistiksel olarak anlamlı farklıık saptanmamıştır.

\section{Kaynaklar}

1. Meier R. Fibre and short chain fatty acids. Sobotka L.(ed). Basics in clinical nutrition. Third edition. Prague: Galen; 2004. p. 176-9.

2. Chang WK, McClave SA, Lee MS, Chao YC. Monitoring bolus nasogastric tube feeding by the Brix value determination and residual volume measurement of gastric contents. JPEN J Parenter Enteral Nutr 2004;28:105-12.

3. Ibáñez J, Peñafiel $A$, Marsé $P$, Jordá $R$, Raurich JM, Mata $F$. Incidence of gastroesophageal reflux and aspiration in mechanically ventilated patients using small-bore nasogastric tubes. JPEN J Parenter Enteral Nutr 2000;24:103-6.

4. Mallampalli A, McClave SA, Snider HL. Defining tolerance to enteral feeding in the intensive care unit. Clin Nutr 2000;19:213-5.

5. Montejo JC, Miñambres E, Bordejé L, Mesejo A, Acosta J, Heras A, et al. Gastric residual volume during enteral nutrition in ICU patients: the REGANE study. Intensive Care Med 2010;36:1386-93.

6. Sakarya M. Enteral nutrisyon. Turkiye Klinikleri J Surg Med Sci 2007;3:51-8. 
7. Powell-Tuck J. Nutritional interventions in critical illness. Proc Nutr Soc 2007;66:16-24

8. Borlase BC, Babineau T, Force R.A, Enteral nutritional support. Grenvik A, Ayres S, HolbRook P, Shoemaker W(eds). Critical Care. $4^{\text {th }}$ ed. Philedelphia, WB Saunders, 1993;1669-74.

9. Demirer S. Yoğun bakım hastalarında beslenme desteği. Turkiye Klinikleri J Surg Med Sci 2007;3:59-63.

10. Okamoto K, Fukatsu K, Ueno C, Shinto E, Hashiguchi $Y$, Nagayoshi $\mathrm{H}$, et al. Tlymphocyte numbers in human gut associated lymphoid tissue are reduced without enteral nutrition. JPEN J Parenter Enteral Nutr 2005:29:56-8.

11. Wildish DE. Enteral formulary management: a cost-effective approach. Can J Diet Pract Res 2006;67:193-8.

12. Pinilla JC, Samphire J, Arnold C, Liu L, Thiessen B. Comparison of gastrointestinal tolerance to two enteral feeding protocols in critically ill patients: a prospective, randomized controlled trial. JPEN J Parenter Enteral Nutr 2001;25:81-6.
13. Spain DA, McClave SA, Sexton LK, Adams JL, Blanford BS, Sullins ME, et al. Infusion protocol improves delivery of enteral tube feeding in the critical care unit. JPEN J Parenter Enteral Nutr 1999;23:288-92.

14. Chang WK, McClave SA, Chao YC. Continuous nasogastric tube feeding: monitoring by combined use of refractometry and traditional gastric residual volumes. Clin Nutr 2004;23:105-12.

15. Mentec H, Dupont H, Bocchetti M, Cani P, Ponche F, Bleichner G. Upper digestive intolerance during enteral nutrition in critically ill patients: frequency, risk factors, and complications. Crit Care Med 2001;29:1955-61.

16. Chow J. Probiotics and prebiotics: A brief overview. J Ren Nutr 2002;12:76-86.

17. Reintam A, Parm P, Kitus R, Kern H, Starkopf J. Gastrointestinal symptoms in intensive care patients. Acta Anaesthesiol Scand 2009:53:318-24. 